\title{
Measuring quality of diabetes care by linking health care system administrative databases with laboratory data
}

\author{
Helena Klomp ${ }^{1}$, Roland F Dyck ${ }^{2,3^{*}}$, Nirmal Sidhu', Paul J Cascagnette ${ }^{1}$, Gary F Teare ${ }^{1,3}$
}

\begin{abstract}
Background: Chronic complications of diabetes can be reduced through optimal glycemic and lipid control as evaluated through measurement of glycosylated hemoglobin (A1C) and low-density lipoprotein cholesterol (LDL-C). We aimed to produce measures of quality of diabetes care in Saskatchewan and to identify sub-groups at particular risk of developing complications.

Findings: Prevalent adult cases of diabetes in 2005/06 were identified from administrative databases and linked with $A 1 C$ and $L D L-C$ tests measured in centralized laboratories. A1C results were performed in 33,927 of 50,713 (66.9\%) diabetes cases identified in Saskatchewan, and LDL-C results were performed in 12,031 of 24,207 (49.7\%) cases identified within the province's two largest health regions. The target A1C of $<=7.0 \%$ and the target LDL-C of $<2.5 \mathrm{mmol} / \mathrm{L}$ were achieved in $48.3 \%$ and $45.1 \%$ of diabetes cases respectively. The proportions were lower among those who were female, First Nations, non-urban, younger and in lower income quintiles. The same groups experienced poorer glycemic control (exception females), and poorer lipid control (exception First Nations people). Among non-Aboriginal people, younger diabetic females were least likely to receive lipid lowering agents.

Conclusions: Linkage of laboratory with administrative data is an effective method of assessing quality of diabetes care on a population basis and to identify sub-groups requiring particular attention. We found that less than $50 \%$ of Saskatchewan people with diabetes achieved optimal glycemic and lipid control. Disparities were most evident among First Nations people and young women. The indicators described can be used to provide standardized information that would support quality improvement initiatives.
\end{abstract}

\section{Background}

Canadians are experiencing an epidemic of diabetes $[1,2]$ that disproportionately affects First Nations people [3,4]. Although this has serious consequences for individuals, families and the health care system largely because of chronic complications, these can be lessened with improved glycemic and lipid control $[5,6]$.

The Canadian Diabetes Association publishes clinical practice guidelines that include target values for glycosylated hemoglobin (A1C) and low-density lipoprotein cholesterol (LDL-C) [7]. We evaluated testing frequency and outcome measures of $\mathrm{A} 1 \mathrm{C}$ and LDL-C indicators to produce population measures of quality of diabetes care

\footnotetext{
* Correspondence: roland.dyck@usask.ca

${ }^{2}$ Department of Medicine, Royal University Hospital, University of

Saskatchewan, 103 Hospital Drive, Saskatoon, S7N 0W8, Canada

Full list of author information is available at the end of the article
}

and to identify sub-groups at particular risk for complications. This was achieved on a population basis through linkage of laboratory data with health care system administrative data.

\section{Methods}

\section{Study Populations}

This 2005/06 population based study of diabetes care in Saskatchewan was approved by the University of Saskatchewan, Saskatoon Health Region and Regina Qu'Appelle Health Region Ethics Review Boards. Study populations were identified from Ministry of Health databases used to administer health care to $99 \%$ of the provincial population [8]. Beneficiaries were sub-divided into First Nations people (FN) and other Saskatchewan residents (OSK) by age and sex. FN are indigenous to Canada and included those registered under Section 6 
of the Indian Act [9]. Most OSK are of European origin but include non-registered FN $(<0.5 \%)$ and Métis (about $5 \%$ ) [10]. The provincial population was approximately one million people and $>10 \%$ were FN [11].

Diabetic adults aged 20 years and older were identified using a validated algorithm [12] based on National Diabetes Surveillance System (NDSS) case definitions [13]. These required one hospitalization with a discharge diagnosis of diabetes (ICD-9 250.x or ICD-10-CA E10E14.xxx), or two physician service claims for diabetes within any 730 day period. Gestational diabetes cases were excluded. We were not able to distinguish between types 1 and 2 diabetes but $<2 \%$ of incident diabetes cases in Canada are $<20$ years [14], the group with the highest type 1 diabetes incidence [15].

We define the diabetes incident year as the first fiscal year (April1 to March 31) in which an individual meets the diabetes case definition when there has been no prior diabetes diagnosis for at least two years. Thereafter, for each year that an individual is covered by Saskatchewan Health, the individual is a prevalent case. Only prevalent cases of diabetes counted on the first day (April 1) of the 2005/06 fiscal year were included in this study; they comprised the core denominators for our analyses.

\section{Linkage of Diabetes Cases with Laboratory Data}

Using encrypted unique identifiers, prevalent cases of diabetes were linked with laboratory data from centralized laboratories in the two largest Health Regions in Saskatchewan (Saskatoon and Regina/Qu'Appelle). This data accounted for nearly $100 \%$ of A1C tests and $50 \%$ of LDL-C tests performed in the province.

\section{Quality of Diabetes Care Indicators}

Because this study predated the 2008 clinical practice guidelines [7], we used an A1C target of $\leq 7.0 \%$ for glycemic control and an LDL-C target of $<2.5 \mathrm{mmol} / \mathrm{L}$ (now $<2.0 \mathrm{mmol} / \mathrm{L}$ ) for lipid control as published in 2003 [16]. A1C testing was recommended at diabetes diagnosis and then 3-4 times per year; LDL-C testing was recommended at diabetes diagnosis and then every 1-3 years as clinically indicated. Finally, we chose an A1C of $>=9.0 \%$ to indicate very poor glycemic control and a LDL-C of $>=2.5 \mathrm{mmol} / \mathrm{L}$ as a level when use of lipid lowering drugs should be considered.

Based on the above, the quality of care indicators were: proportion of diabetes cases tested for $\mathrm{A} 1 \mathrm{C}$ in 2005/06; of those tested, the proportion with a most recent $\mathrm{A} 1 \mathrm{C}<=7.0 \%$, a most recent $\mathrm{A} 1 \mathrm{C}>=9.0 \%$ and the mean of most recent $\mathrm{A} 1 \mathrm{C}$ tests; proportion with $>=$ $2 \mathrm{~A} 1 \mathrm{C}$ tests/year; proportion with $>=3 \mathrm{~A} 1 \mathrm{C}$ tests/year; proportion of diabetes cases with $\mathrm{A} 1 \mathrm{C}<=7.0 \%$ by frequency of testing $(1,2,3,4+$ tests/year); proportion of diabetes cases ever tested for LDL-C in 2005/06; of those, the proportion with a latest LDL-C $<2.5 \mathrm{mmol} / \mathrm{L}$, and the mean LDL-C; and proportion of OSK diabetes cases with an LDL-C $>=2.5 \mathrm{mmol} / \mathrm{L}$ dispensed a lipid lowering drug (not available for FN). Overall results as well as by sex, ethnicity, location, age group and income quintile were calculated. Detailed descriptions of indicator derivations can be found in the Saskatchewan Health Quality Council 2008 Quality Insight report's Technical Appendix [17].

\section{Analyses}

Most comparisons were made between groups within specific demographic sub-populations. Mean A1C and LDL-C values were compared using two tailed t-tests for two groups and one way Anova for multiple groups. For between group comparisons, we chose a reference group and calculated OR's with $95 \%$ confidence intervals for the remaining groups. Tests for linear trend (one sided and two sided) were used to compare within group proportions of diabetes cases with $\mathrm{A} 1 \mathrm{C}<=7.0 \%$ by frequency of testing. Data abstraction and analyses were carried out using SAS software version 9.1.3. A p value of $<=0.05$ was considered significant.

\section{Results}

Of the 50,713 prevalent diabetes cases in Saskatchewan during 2005/06 (Table 1), 24,188 were female (47.7\%) and 6,184 were FN (12.2\%). A majority (53.5\%) were urban dwellers and $81 \%$ were $>=50$ years. Almost half were in the lowest two income quintiles (48.3\%).

Overall, $66.9 \%$ of people with diabetes had an A1C level done during 2005/06. Younger, female, non-urban people and those with lowest incomes were less likely to have an A1C test compared to their respective counterparts. However, the diabetic groups least likely to have an $\mathrm{A} 1 \mathrm{C}$ test were those under age $40(53.7 \%)$ and FN (59\%). With the exception of females, the same demographic groups with fewest $\mathrm{A} 1 \mathrm{C}$ tests also experienced the poorest $\mathrm{A} 1 \mathrm{C}$ results. FN and those under age 40 exhibited the worst results with mean $\mathrm{A} 1 \mathrm{Cs}$ of $8.0 \%$ and $8.1 \%$ respectively. The group with the best A1C profile were those aged $70+(54.3 \%$ had $\mathrm{A} 1 \mathrm{Cs}<=7 \%, 7.1 \%$ had $\mathrm{A} 1 \mathrm{Cs}>=9 \%$ and the mean $\mathrm{A} 1 \mathrm{C}$ was $7.2 \%)$.

Overall, $38.4 \%$ of adults with diabetes had $>=2$ and $17.5 \%$ had $>=3$ A1C tests during 2005/06 (Table 2). Results were similar between males and females. Nonurban people were less likely than urban dwellers to have $>1 \mathrm{~A} 1 \mathrm{C}$ tests during the year. However, those tested least frequently were FN.

Overall, the proportion of diabetic people with target A1Cs decreased from $49.1 \%$ of those tested once to $47.3 \%$ of those tested $>=4$ times (Table 3 ). This downward trend was mirrored in males and OSK. Only FN 
Table 1 Outcomes of A1C testing among Saskatchewan adults with Diabetes by Demographic Characteristics

\begin{tabular}{|c|c|c|c|c|c|c|c|c|c|}
\hline \multirow[t]{2}{*}{ Characteristic } & \multirow{2}{*}{$\begin{array}{c}\text { Number of persons with } \\
\text { diabetest }\end{array}$} & \multicolumn{2}{|c|}{ Tested for A1C } & \multirow{2}{*}{$\begin{array}{c}\text { Number of persons } \\
\text { tested }\end{array}$} & \multicolumn{2}{|c|}{$\mathrm{A} 1 \mathrm{C}<=7.0 \%$} & \multicolumn{2}{|c|}{$A 1 C>=9.0 \%$} & \multirow{2}{*}{$\begin{array}{l}\text { Mean } \\
\text { A1C }\end{array}$} \\
\hline & & $\%$ & $\begin{array}{l}\text { OR }(95 \% \\
\text { Cl) }\end{array}$ & & $\%$ & $\begin{array}{c}\text { OR }(95 \% \\
\text { Cl) }\end{array}$ & $\%$ & $\begin{array}{c}\text { OR }(95 \% \\
\text { Cl) }\end{array}$ & \\
\hline ALL SASK & 50713 & 66.9 & & 33920 & 48.3 & & 12.6 & & 7.4 \\
\hline female & 24188 & 66.0 & $\begin{array}{l}0.95(0.92- \\
0.99)\end{array}$ & 15971 & 50.4 & $\begin{array}{c}1.16(1.11- \\
1.21)\end{array}$ & 12.3 & $\begin{array}{c}0.95(0.89- \\
1.01)\end{array}$ & $7.4^{1}$ \\
\hline male* & 26525 & 67.7 & & 17949 & 46.5 & & 12.9 & & 7.5 \\
\hline \multicolumn{10}{|l|}{ ETHNICITY } \\
\hline FN & 6184 & 59.0 & $\begin{array}{l}0.72(0.68- \\
0.76)\end{array}$ & 3646 & 40.6 & $\begin{array}{l}0.80(0.74- \\
0.86)\end{array}$ & 25.5 & $\begin{array}{l}2.05(1.88- \\
2.24)\end{array}$ & $8.0^{1}$ \\
\hline OSK & 44529 & 68.0 & & 30274 & 49.3 & & 11.1 & & 7.4 \\
\hline \multicolumn{10}{|l|}{ LOCATION } \\
\hline urban* & 27147 & 68.4 & & 18563 & 49.9 & & 11.9 & & 7.4 \\
\hline non-urban & 23508 & 65.2 & $\begin{array}{l}0.86(0.83- \\
0.89)\end{array}$ & 15333 & 46.5 & $\begin{array}{l}0.86(0.82- \\
0.90)\end{array}$ & 13.6 & $\begin{array}{l}1.23(1.15- \\
1.31)\end{array}$ & $7.5^{1}$ \\
\hline \multicolumn{10}{|l|}{ AGE (years) } \\
\hline $20-29$ & 686 & 51.2 & $\begin{array}{l}0.55(0.47- \\
0.64)\end{array}$ & 351 & 40.2 & $\begin{array}{l}0.56(0.45- \\
0.69)\end{array}$ & 24.5 & $\begin{array}{c}4.26(3.31- \\
5.49)\end{array}$ & $8.1^{1}$ \\
\hline 30-39 & 2652 & 54.3 & $\begin{array}{l}0.62(0.57- \\
0.67)\end{array}$ & 1439 & 37.0 & $\begin{array}{l}0.49(0.44- \\
0.55)\end{array}$ & 27.4 & $\begin{array}{l}\text { 4.96(4.33- } \\
5.67)\end{array}$ & $8.1^{1}$ \\
\hline $40-49$ & 6287 & 62.1 & $\begin{array}{c}0.85(0.80- \\
0.90)\end{array}$ & 3902 & 42.1 & $\begin{array}{c}0.61(0.57- \\
0.66)\end{array}$ & 20.6 & $\begin{array}{c}3.39(3.06- \\
3.76)\end{array}$ & $7.8^{1}$ \\
\hline $50-59$ & 10663 & 69.8 & $\begin{array}{l}1.20(1.4- \\
1.26)\end{array}$ & 7443 & 44.4 & $\begin{array}{c}0.68(0.64- \\
0.72)\end{array}$ & 16.6 & $\begin{array}{l}2.58(2.36- \\
2.83)\end{array}$ & $7.6^{1}$ \\
\hline $60-69$ & 11596 & 72.5 & $\begin{array}{l}1.37(1.30- \\
1.44)\end{array}$ & 8408 & 48.1 & $\begin{array}{l}0.79(0.74- \\
0.83)\end{array}$ & 10.6 & $\begin{array}{l}1.54(1.40- \\
1.70)\end{array}$ & $7.4^{1}$ \\
\hline$\geq 70^{*}$ & 18829 & 65.7 & & 12377 & 54.3 & & 7.1 & & 7.2 \\
\hline \multicolumn{10}{|l|}{$\begin{array}{l}\text { INCOME } \\
\text { QUINTILE }\end{array}$} \\
\hline lowest & 12991 & 63.1 & $\begin{array}{l}0.76(0.72- \\
0.81)\end{array}$ & 8195 & 46.0 & $\begin{array}{l}0.81(0.75- \\
0.86)\end{array}$ & 15.7 & $\begin{array}{l}1.53(1.38- \\
1.69)\end{array}$ & $7.6^{1}$ \\
\hline second & 11496 & 66.3 & $\begin{array}{l}0.86(0.82- \\
0.92)\end{array}$ & 7626 & 47.1 & $\begin{array}{l}0.83(0.78- \\
0.89)\end{array}$ & 13.4 & $\begin{array}{l}1.31(1.18- \\
1.45)\end{array}$ & $7.5^{1}$ \\
\hline third & 8615 & 68.8 & $\begin{array}{l}0.96(0.90- \\
1.02)\end{array}$ & 5923 & 50.3 & $\begin{array}{l}0.94(0.88- \\
1.01)\end{array}$ & 10.9 & $\begin{array}{c}1.06(0.94- \\
1.19)\end{array}$ & $7.3^{1}$ \\
\hline fourth & 7589 & 68.8 & $\begin{array}{l}0.95(0.89- \\
1.02)\end{array}$ & 5220 & 48.2 & $\begin{array}{l}0.87(0.81- \\
0.94)\end{array}$ & 11.3 & $\begin{array}{l}1.08(0.96- \\
1.22)\end{array}$ & $7.4^{1}$ \\
\hline highest* & 9436 & 69.9 & & 6593 & 51.2 & & 10.7 & & 7.3 \\
\hline
\end{tabular}

All rates are crude rates

*Reference category

tIncludes prevalent diabetes cases aged 20 years and older at beginning of fiscal year 2005/06

Values in this table are based on the last $\mathrm{A} 1 \mathrm{C}$ result reported for year

${ }^{1} \mathrm{p}<=0.0001$

experienced an improvement in target A1C by frequency of testing (38.9\% of those tested once to $44.9 \%$ of those tested $>=4$ times).

Table 4 shows results of LDL-C testing among adults with diabetes in Saskatchewan's two most populous Health Regions. Of the 24,207 prevalent diabetes cases, 11,294 were female $(46.7 \%)$ and 2,321 were FN (9.6\%).
Most were urban (77.3\%) and the majority were aged $50+(80.3 \%)$. Almost half (48.7\%) were in the lowest two income quintiles.

Overall, $49.7 \%$ of diabetic adults had at least one LDL$\mathrm{C}$ test during 2005/06. Younger, female, non-urban people and those with lowest incomes were less likely to have an LDL-C test than reference groups. However, 
Table 2 Frequency of A1C testing among Saskatchewan adults with Diabetes by Demographic Characteristics

\begin{tabular}{|c|c|c|c|c|c|c|c|}
\hline & \multirow[t]{2}{*}{ Number of persons with diabetes* } & \multicolumn{3}{|c|}{ Persons with $>=2 \mathrm{~A} 1 \mathrm{C}$ tests/year } & \multicolumn{3}{|c|}{ Persons with $>=3 \mathrm{~A} 1 \mathrm{C}$ tests/year } \\
\hline & & number & $\%$ & OR $(95 \% \mathrm{Cl})$ & number & $\%$ & OR $(95 \% \mathrm{Cl})$ \\
\hline ALL SASK & 48200 & 18256 & 38.4 & & 8436 & 17.5 & \\
\hline female & 23028 & 8767 & 38.1 & $0.99(0.95-1.03)$ & 4000 & 17.4 & $1.00(0.95-1.04)$ \\
\hline malet & 25172 & 9759 & 38.8 & & 4436 & 17.6 & \\
\hline \multicolumn{8}{|l|}{ ETHNICITY } \\
\hline FN & 5959 & 1747 & 29.3 & $0.69(0.65-0.74)$ & 692 & 11.6 & $0.65(0.60-0.71)$ \\
\hline OSK† & 42241 & 16779 & 39.7 & & 7744 & 18.3 & \\
\hline \multicolumn{8}{|l|}{ LOCATION } \\
\hline urbant & 25809 & 10351 & 40.1 & & 4855 & 18.8 & \\
\hline non-urban & 22338 & 8160 & 36.5 & $0.85(0.82-0.88)$ & 3572 & 16.0 & $0.81(0.77-0.85)$ \\
\hline
\end{tabular}

All rates are crude rates

*Includes prevalent diabetes cases aged 20 years and older at beginning of fiscal year 2005/06 and who survived the year with SK Ministry of Health insurance coverage

†Reference category

those least likely to have an LDL-C test were younger people and FN (29.2\% versus $51.8 \%$ of OSK). Females displayed among the poorest LDL-C outcomes with only $41.3 \%$ achieving target LDL-C levels compared to $48.2 \%$ of males. Mean LDL-C was also poorer for females $(2.8 \mathrm{mmol} / \mathrm{L})$ compared to males $(2.6 \mathrm{mmol} / \mathrm{L})$. In contrast to A1C findings, FN and non-urban diabetic people were more likely to achieve target LDL-C levels than their OSK and urban counterparts.

During 2005/06, 41,934 diabetic OSK lived in Saskatchewan for the entire year. Of those, $36.9 \%$ were prescribed a lipid lowering agent compared to $38.6 \%$ of 20,714 diabetic OSK living in Saskatchewan's two most populous Health Regions. Table 5 shows that 6,914 diabetic OSK in the two Health Regions had a most recent LDL-C level $>=2.5 \mathrm{mmol} / \mathrm{L}$, but only $39.2 \%$ of those received a lipid lowering drug. Although no significant differences were found by location and income quintile, there was a trend for better treatment rates with increasing income. The lowest treatment rates were observed in the oldest and youngest subjects, and among women. However, both males $(27.0 \%)$ and females (18.8\%) under age 40 were least likely to receive treatment.

\section{Discussion}

We measured A1C and LDL-C quality of care indicators in Saskatchewan's diabetic population by linking health care system administrative data with laboratory data. While over $2 / 3$ of people with diabetes received A1C testing, less than $50 \%$ achieved target levels and $12.6 \%$ exhibited very poor glycemic control. Almost $50 \%$ of the study population received LDL-C testing but only $45.1 \%$ of those achieved target levels and only $39.2 \%$ of those

Table 3 Outcomes of A1C Testing by Frequency of Testing among Saskatchewan Adults with Diabetes

\begin{tabular}{|c|c|c|c|c|c|c|c|c|c|}
\hline & \multicolumn{2}{|c|}{$\begin{array}{c}\text { Persons with } \\
\text { only } 1 \mathrm{~A} 1 \mathrm{C} \text { test/ } \\
\text { year }\end{array}$} & \multicolumn{2}{|c|}{$\begin{array}{c}\text { Persons with } 2 \text { A1C } \\
\text { tests/year }\end{array}$} & \multicolumn{2}{|c|}{$\begin{array}{c}\text { Persons with } 3 \mathrm{~A} 1 \mathrm{C} \\
\text { tests/year }\end{array}$} & \multicolumn{2}{|c|}{$\begin{array}{c}\text { Persons with }>=4 \\
\text { A1C tests/year }\end{array}$} & \multirow[t]{2}{*}{ Test for linear trend } \\
\hline & $\mathrm{n}^{*}$ & $\begin{array}{l}\% \mathrm{~A} 1 \mathrm{C} \\
<=7.0\end{array}$ & $\mathrm{n}+$ & $\%$ A1C $<=7.0$ & $\mathrm{n}+$ & $\% A 1 C<=7.0$ & $\mathrm{n}+$ & $\% A 1 C<=7.0$ & \\
\hline ALL SASK & 15034 & 49.1 & 10336 & 48.0 & 5371 & 47.5 & 3179 & 47.3 & \\
\hline female & 7059 & 51.3 & 4864 & 49.8 & 2581 & 49.1 & 1467 & 49.7 & $p=0.0259(1$ sided $)=0.0517(2$ sided $)$ \\
\hline Male & 7975 & 47.1 & 5472 & 46.4 & 2790 & 46.0 & 1712 & 45.3 & $p=0.0711(1$ sided $)=0.1422(2$ sided $)$ \\
\hline \multicolumn{10}{|l|}{ ETHNICITY } \\
\hline FN & 1866 & 38.9 & 1073 & 41.0 & 453 & 44.8 & 254 & 44.9 & $p=0.0035(1$ sided $)=0.0070(2$ sided $)$ \\
\hline OSK & 13168 & 50.5 & 9263 & 48.8 & 4918 & 47.7 & 2925 & 47.6 & $p=0.0001(1$ sided $)=0.0001(2$ sided $)$ \\
\hline
\end{tabular}

All rates are crude rates

* Denominator is all prevalent diabetes cases aged 20 years and older at the beginning of fiscal year 2005-06

† Includes prevalent diabetes cases defined at beginning of fiscal year 2005/06 and who survived the year with SK Ministry of Health insurance coverage

$A 1 C$ values in this table are based on the last $A 1 C$ result reported for year 
Table 4 LDL Cholesterol Indicator outcomes among Diabetic adults in Two Saskatchewan Health regions by Demographic Characteristics

\begin{tabular}{|c|c|c|c|c|c|c|c|c|}
\hline & \multirow[t]{2}{*}{$\begin{array}{c}\text { Number of persons with } \\
\text { diabetest }\end{array}$} & \multicolumn{2}{|c|}{ Tested for LDL-C } & \multirow[t]{2}{*}{$\begin{array}{c}\text { Number of persons } \\
\text { tested }\end{array}$} & \multicolumn{2}{|c|}{$\begin{array}{c}\mathrm{LDL}-\mathrm{C}<2.5 \\
\mathrm{mmol} / \mathrm{L}\end{array}$} & \multicolumn{2}{|c|}{ Mean LDL-C } \\
\hline & & $\%$ & OR $(95 \% \mathrm{Cl})$ & & $\%$ & OR $(95 \% \mathrm{Cl})$ & $\underset{\mathrm{L}}{\mathrm{Mmol} /}$ & Significance \\
\hline TOTAL & 24207 & 49.7 & & 12019 & 45.1 & & 2.7 & \\
\hline female & 11294 & 47.6 & $\begin{array}{l}0.89(0.85- \\
0.94)\end{array}$ & 5379 & 41.3 & $\begin{array}{l}0.76(0.78- \\
0.81)\end{array}$ & 2.8 & $p<0.0001$ \\
\hline male* & 12913 & 51.4 & & 6640 & 48.2 & & 2.6 & \\
\hline \multicolumn{9}{|l|}{ ETHNICITY } \\
\hline FN & 2321 & 29.2 & $\begin{array}{l}0.38(0.35- \\
0.42)\end{array}$ & 677 & 47.9 & $\begin{array}{l}1.26(1.07- \\
1.47)\end{array}$ & 2.6 & $p=0.19$ \\
\hline OSK $K^{*}$ & 21886 & 51.8 & & 11342 & 44.9 & & 2.7 & \\
\hline \multicolumn{9}{|l|}{ LOCATION } \\
\hline urban* & 18702 & 57.1 & & 10679 & 45.0 & & 2.7 & \\
\hline non-urban & 5476 & 24.1 & $\begin{array}{l}0.23(0.22- \\
0.25)\end{array}$ & 1322 & 46.2 & $\begin{array}{l}1.03(0.92- \\
1.15)\end{array}$ & 2.7 & $p=0.18$ \\
\hline \multicolumn{9}{|l|}{ AGE (years) } \\
\hline $20-29$ & 358 & 29.1 & $\begin{array}{l}0.49(0.39- \\
0.62)\end{array}$ & 104 & 42.3 & $\begin{array}{l}0.84(0.57- \\
1.25)\end{array}$ & 2.8 & \\
\hline 30-39 & 1379 & 35.1 & $\begin{array}{l}0.64(0.57- \\
0.72)\end{array}$ & 484 & 39.5 & $\begin{array}{l}0.75(0.62- \\
0.91)\end{array}$ & 2.8 & \\
\hline $40-49$ & 3040 & 46.8 & $\begin{array}{l}1.04(0.96- \\
1.13)\end{array}$ & 1423 & 42.1 & $\begin{array}{l}0.82(0.73- \\
0.93)\end{array}$ & 2.7 & \\
\hline $50-59$ & 5268 & 54.5 & $\begin{array}{l}1.41(1.32- \\
1.51)\end{array}$ & 2871 & 43.4 & $\begin{array}{l}0.85(0.77- \\
0.94)\end{array}$ & 2.7 & $p=0.0002$ \\
\hline $60-69$ & 5428 & 57.9 & $\begin{array}{l}1.62(1.51- \\
1.74)\end{array}$ & 3144 & 46.7 & $\begin{array}{l}0.98(0.89- \\
1.07)\end{array}$ & 2.7 & \\
\hline$\geq 70^{*}$ & 8734 & 45.7 & & 3993 & 46.9 & & 2.7 & \\
\hline \multicolumn{9}{|l|}{$\begin{array}{l}\text { INCOME } \\
\text { QUINTILE }\end{array}$} \\
\hline lowest & 6170 & 45.8 & $\begin{array}{l}0.74(0.69- \\
0.81)\end{array}$ & 2826 & 44.1 & $\begin{array}{l}0.91(0.81- \\
1.02)\end{array}$ & 2.7 & \\
\hline second & 5630 & 48.4 & $\begin{array}{l}0.81(0.74- \\
0.88)\end{array}$ & 2726 & 44.6 & $\begin{array}{l}0.91(0.81- \\
1.02)\end{array}$ & 2.7 & \\
\hline third & 4499 & 49.9 & $\begin{array}{l}0.85(0.78- \\
0.92)\end{array}$ & 2247 & 45.1 & $\begin{array}{l}0.93(0.82- \\
1.04)\end{array}$ & 2.7 & $p<0.02$ \\
\hline fourth & 4044 & 52.3 & $\begin{array}{l}0.93(0.85- \\
1.01)\end{array}$ & 2116 & 45.1 & $\begin{array}{l}0.92(0.81- \\
1.03)\end{array}$ & 2.7 & \\
\hline highest* & 3770 & 54.8 & & 2067 & 47.4 & & 2.6 & \\
\hline
\end{tabular}

All rates are crude rates

* Reference category

† Includes prevalent diabetes cases aged 20 years and older at beginning of fiscal year 2005/06 in Saskatchewan's two largest Health Regions

with values above the target of $2.5 \mathrm{mmol} / \mathrm{L}$ were prescribed a lipid lowering drug.

Diabetic adults who were female, FN, non-urban, younger or in lower income quintiles were less likely to receive $\mathrm{A} 1 \mathrm{C}$ and $\mathrm{LDL}-\mathrm{C}$ testing. Apart from females, the same groups also experienced poorer glycemic control. While younger subjects and those with lower incomes also displayed poorer LDL-C results, the largest disparity was observed between sexes. Females had higher mean LDL-C concentrations and were less likely to achieve target LDL-C levels. Despite that, diabetic OSK females with sub-optimal LDL-C were the group least likely to receive a lipid lowering agent. This was particularly evident in younger women, so likely included individuals with type 1 diabetes. A somewhat unexpected finding was that FN exhibited better LDL-C profiles than OSK. 
Table 5 Use of Lipid Lowering Drugs among Diabetic OSK With LDL-C >= 2.5 MMOL/L by Demographic Characteristics

\begin{tabular}{|c|c|c|c|c|}
\hline & $\begin{array}{c}\text { Persons with } \\
\text { LDL-C } \geq 2.5 \mathrm{mmol} / \mathrm{L} \dagger\end{array}$ & Persons dispensed a lipid lowering drug & Crude rate (\%) & OR $(95 \% \mathrm{Cl})$ \\
\hline TOTAL & 6914 & 2711 & 39.2 & \\
\hline \multicolumn{5}{|c|}{ AGE (years) Female } \\
\hline 20-39 & 165 & 31 & 18.8 & $0.38(0.26-0.58)$ \\
\hline $40-49$ & 389 & 123 & 31.6 & $0.77(0.60-0.98)$ \\
\hline $50-59$ & 723 & 305 & 42.2 & $1.21(1.00-1.46)$ \\
\hline 60-69 & 795 & 329 & 41.4 & $1.17(0.97-1.41)$ \\
\hline$\geq 70^{*}$ & 1157 & 435 & 37.6 & \\
\hline \multicolumn{5}{|c|}{ AGE (years) Male } \\
\hline 20-39 & 152 & 41 & 27.0 & $0.72(0.50-1.06)$ \\
\hline $40-49$ & 428 & 174 & 40.7 & $1.34(1.07-1.69)$ \\
\hline 50-59 & 978 & 442 & 45.2 & $1.61(1.35-1.93)$ \\
\hline $60-69$ & 1003 & 451 & 45.0 & $1.60(1.34-1.91)$ \\
\hline$\geq 70^{*}$ & 1124 & 380 & 33.8 & \\
\hline \multicolumn{5}{|l|}{ LOCATION } \\
\hline urban* & 6196 & 2416 & 39.0 & \\
\hline non-urban & 704 & 288 & 40.9 & $1.09(0.9-1.3)$ \\
\hline \multicolumn{5}{|c|}{ INCOME QUINTILE } \\
\hline lowest & 1544 & 569 & 36.9 & $0.92(0.79-1.08)$ \\
\hline second & 1566 & 606 & 38.7 & $0.97(0.83-1.13)$ \\
\hline third & 1320 & 515 & 39.0 & $0.96(0.82-1.13)$ \\
\hline fourth & 1267 & 525 & 41.4 & $1.05(0.90-1.24)$ \\
\hline highest* & 1191 & 482 & 40.5 & \\
\hline
\end{tabular}

*Reference category

Drug prescribing data was not available for FN, hence, analysis for lipid lowering prescribing indicators was limited to OSK Data are stratified by sex because age-sex interaction was present

† Sub-group of prevalent diabetes cases aged 20 years and older at beginning of fiscal year 2005/06 in Saskatchewan's two largest Health Regions

In the context of overall evidence for poorer quality of diabetes care, this observation suggests that there may be underlying differences in lipid metabolism between FN and OSK [18].

The proportion of diabetic people achieving target A1C levels decreased with frequency of testing among OSK but increased among FN. The reasons behind the former finding are complex but possibly explained in part by more frequent follow-up care in those with more brittle or complicated diabetes histories. In contrast, the small numbers of $\mathrm{FN}$ with more frequent A1C testing likely represented a subgroup with better diabetes care. This suggests that the overall poorer glycemic control experienced by FN may be subject to improvement through closer monitoring.

Although some of the statistically significant differences found here (particularly for mean A1C and LDL-C) may not be clinically problematic, it is important to highlight that the poorest overall results with respect to frequency of testing and achievement of target values, occurred among diabetic FN people and were substantive. While not unexpected, these findings provide evidence for ethnic-based disparities in quality of diabetes care. This is reflected in higher rates of many diabetes complications including amputations, strokes and end stage renal disease, as well as in higher mortality rates among $\mathrm{FN}$ as we have recently shown using the same methodology [19]. Although the reasons behind these disparities are perplexing in the context of a universal health care system, a recent national survey of diabetes care in FN communities shows promise in elucidating at least some of the underlying problems by examining individual level factors [20]. Furthermore, these sobering findings and their causes are highly relevant to other indigenous and developing populations who are also experiencing disproportionate rates of diabetes and diabetes complications [21].

Strengths of this study include employment of a validated algorithm to identify diabetes cases [12], inclusion of total Saskatchewan populations, ability to carry out a linkage between laboratory and health care system administrative data, and the ability to sub-divide the population by ethnicity. A significant limitation in the 
use of secondary data to conduct diabetes research is the unavailability of important individual level health determinants such as smoking, hypertension, and obesity as well as the inability to determine the impact of acculturation on First Nations people. Other limitations included an inability to identify people of Aboriginal heritage other than FN, but this reduces the true differences between FN and OSK. Second, identifying cases using administrative data may underestimate the incidence and prevalence of diabetes [12]. Third, although we could not differentiate between types 1 and 2 diabetes, most Canadian adults with diabetes have T2DM [14]; the proportion is even higher for FN [15]. Nonetheless, it is likely that the A1C and LDL-C indicator results for younger people with diabetes are partly attributable to OSK with type 1 diabetes. Finally, there may be overlap between the demographic groups that we have described. In particular, poorer results for FN in A1C indicators may be partly related to younger age and lower incomes (or vice versa). However, that would not explain the poor results among young OSK (particularly females) regarding treatment with lipid lowering agents.

\section{Conclusions}

Linkage of laboratory data with health care system administrative data can be used to provide standardized information for people with diabetes on a population basis that can be used to identify deficiencies in care and support quality improvement initiatives. The potential to do so exists throughout Canada and other jurisdictions with universal health care systems and/or electronic medical records serving large patient groups. For example, a recent study described the utilization and outcomes of $\mathrm{A} 1 \mathrm{C}$ testing among people with diabetes in eastern Ontario [22]. Although their results were consistent with those reported here, they did not provide information for FN.

We have now shown that less than $50 \%$ of diabetes cases in Saskatchewan achieved optimal glycemic and lipid control and even smaller proportions were tested as frequently as recommended. Furthermore, disparities were most evident among FN who exhibited substantially lower testing rates and poorer glycemic control than others. The fact that significant gaps exist between evidence-based guidelines for diabetes care and their implementation is a cause for concern. These findings should provide an impetus for understanding those gaps, and for developing and monitoring new strategies designed to improve the quality of diabetes care.

\section{Acknowledgements}

This study was supported by internal funding from the Saskatchewan Health Quality Council and the University of Saskatchewan.
DISCLAIMER: This study is based in part on non-identifiable data provided by the Saskatchewan Ministry of Health. The interpretations and conclusions contained herein are not intended to represent those of the Government of Saskatchewan or the Saskatchewan Ministry of Health.

\section{Author details}

${ }^{1}$ The Division of Quality Measurement and Analysis, Saskatchewan Health Quality Council, 241-111 Research Drive, Saskatoon, S7N 3R2, Canada. ${ }^{2}$ Department of Medicine, Royal University Hospital, University of Saskatchewan, 103 Hospital Drive, Saskatoon, S7N 0W8, Canada. ${ }^{3}$ Department of Community Health and Epidemiology, Royal University Hospital, University of Saskatchewan, 103 Hospital Drive, Saskatoon, S7N OW8, Canada.

\section{Authors' contributions}

HK conceived the study, acquired the data, participated in its design and coordination, interpreted the data and helped to draft the manuscript. RD helped to conceive the study, participated in its design and coordination, interpreted the data and drafted the manuscript. NS and PC participated in the design of the study and performed the statistical analyses. GT participated in the design of the study, oversaw and coordinated the analyses, and interpreted the data. All authors read and approved the final manuscript.

\section{Competing interests}

The authors declare that they have no competing interests.

Received: 9 March 2010 Accepted: 31 August 2010

Published: 31 August 2010

\section{References}

1. Wild S, Roglic G, Green A, Sicree R, King H: Global prevalence of diabetes: estimates for the year 2000 and projections for 2030. Diabetes Care 2004, 27(5):1047-1053.

2. Public Health Agency of Canada: Diabetes in Canada: Highlights from the National Diabetes Surveillance System, 2004-2005. Ottawa, PHAC 2008.

3. Dyck RF, Osgood N, Lin TH, Gao A, Stang MR: Epidemiology of diabetes mellitus among First Nations and non-First Nations adults. Can Med Assoc J 2010, 182(3):249-256.

4. Young TK, Reading J, Elias B, O'Neil J: Type 2 diabetes mellitus in Canada's First Nations: status of an epidemic in progress. Can Med Assoc J 2000, 163(5):561-566.

5. The Diabetes Control and Complications Trial Research Group: The effect of intensive treatment of diabetes on the development and progression of long-term complications in insulin dependent diabetes mellitus. $N$ Engl J Med 1993, 329:977-986.

6. Heart Protection Study Collaborative Group: MRC/BHF Heart Protection Study of cholesterol lowering with simvastatin in 20,536 high-risk individuals: a randomized placebo controlled trial. Lancet 2002, 360:7-22.

7. Canadian Diabetes Association Clinical Practice Guidelines Expert Committee: Canadian Diabetes Association 2008 clinical practice guidelines for the prevention and management of diabetes in Canada. Can J Diabetes 2008, 32(Supplement 1).

8. Downey W, Stang M, Beck P, Osei W, Nichol J: Health services databases in Saskatchewan. Pharmacoepidemiology Mississauga (ON): John Wiley and Sons, 4 2005, 296.

9. Clatworthy SJ: Re-assessing the population impacts of Bill C-31. Strategic Research and Analysis Directorate. Indian and Northern Affairs Canada. Ottawa Ontario 2004.

10. Statistics Canada. 2002. 2001 census Aboriginal population profiles Released June 17, 2003. Last modified: 2005-11-30. Statistics Canada Catalogue no. 93F0043XIE.

11. Saskatchewan Health covered population 2007: Saskatchewan Health, Regina. 2007 [http://www.health.gov.sk.ca/covered-population2007/csv. $\mathrm{htm}]$.

12. Hux JE, Ivis F, Flintoft V, Bica A: Diabetes in Ontario: determination of prevalence and incidence using a validated administrative data algorithm. Diabetes Care 2002, 25:512-516.

13. Public Health Agency of Canada: Diabetes in Canada: Highlights from the National Diabetes Surveillance System, 2004-2005. Ottawa, PHAC 2008. 
14. Report from the National Diabetes Surveillance System: Diabetes in Canada. 2008 [http://www.ndss.gc.ca].

15. Onkamo $P$, Väänänen $S$, Karvonen $M$, Tuomilehto $\mathrm{J}$ : Worldwide increase in incidence of type 1 diabetes - the analysis of the data on published incidence trends. Diabetologia 1999, 42:1395-1403.

16. Canadian Diabetes Association Clinical Practice Guidelines Expert Committee: Canadian Diabetes Association 2003 clinical practice guidelines for the prevention and management of diabetes in Canada. Can J Diabetes 2003, 27(Supplement 1).

17. Klomp H, Sidhu N, Cascagnette PJ, Teare G: Quality Insight - Technical Appendix. Saskatoon: Health Quality Council 2008 [http://www.hqc.sk.ca].

18. Harris SB, Zinman B, Hanley A, Gittelsohn J, Hegele R, Connelly PW, Shah B, HuX JE: The impact of diabetes on cardiovascular risk factors and outcomes in a native Canadian population. Diabetes Res Clin Pract 2002, 55(2):165-173.

19. Klomp H, Cascagnette P, Sidhu N, Quail J, Gezer R, Teare G: Quality Insight Report: Diabetes Care - Detailed data tables and figures for all indicators. Saskatoon: Health Quality Council 2008 [http://www.hqc.sk.ca].

20. Harris SB, Naqshbandi M, Hanley AJG, Bhattacharyya OK, Esler JG, Zinman B: Comparison of the clinical management of type 2 diabetes in Canada's First Nations peoples to national guidelines: The CIRCLE Study. Can J Diabetes 2009, 33(3), 0-0362, 202.

21. Wild S, Roglic G, Green A, Sicree R, King H: Global prevalence of diabetes: estimates for the year 2000 and projections for 2030. Diabetes Care 2004, 27(5):1047-1053.

22. Woodward G, van Walraven C, Hux JE: Utilization and outcomes of HbA1C testing: a population based study. Can Med Assoc J 2006, 174(3):327-329.

doi:10.1186/1756-0500-3-233

Cite this article as: Klomp et al:: Measuring quality of diabetes care by linking health care system administrative databases with laboratory data. BMC Research Notes 2010 3:233.

\section{Submit your next manuscript to BioMed Central and take full advantage of:}

- Convenient online submission

- Thorough peer review

- No space constraints or color figure charges

- Immediate publication on acceptance

- Inclusion in PubMed, CAS, Scopus and Google Scholar

- Research which is freely available for redistribution

Submit your manuscript at www.biomedcentral.com/submit 